\title{
Integrating mindfulness and character strengths for improved wellbeing, stress, and relationships: A mixed-methods analysis of Mindfulness-Based Strengths Practice
}

\author{
Karen Whelan-Berry · Ryan Niemiec
}

\begin{abstract}
The integration of mindfulness and character strengths is an emerging area of research and practice. The evidence-based, 8-week program, Mindfulness-Based Strengths Practice (MBSP) represents a unique approach in that the starting point and focus is on what is best in human beings - their character strengths. These qualities are then leveraged to improve one's meditation practice or area of mindful living (referred to as "strong mindfulness") and in turn, mindfulness is used as a lens for deepening awareness and use of strengths (referred to as "mindful strengths use"). While early controlled studies find MBSP to elicit well-being and reduce stress, and find it to be superior to popular mindfulness programs for different outcomes, we are not aware of any published qualitative analyses examining the MBSP participant's experience. This study offers insights from a large international sample and extends the empirical data on MBSP, including the novel finding of benefit for building positive relationships, as well as confirming other findings such as the most common obstacles people confront in mindfulness practices. Additional areas discussed using qualitative and quantitative findings include the most beneficial mindfulness/character strengths practices, the use of inward and outward-oriented practices, cognizance of the integration of mindfulness and character strengths, and self-reported positive outcomes, including substantial benefits to stress and problem management and boosts to meaning, purpose, engagement, accomplishment, and sense of self.
\end{abstract}

Keywords: mindfulness-based strengths practice; character strengths; positive interventions; strong mindfulness; mindful strengths use; mindful living; positive relationships

\section{Introduction}

The integration of mindfulness and character strengths is a relatively new area of research and practice, however, studies are showing significant potential for this integration in the workplace/organizations (Niemiec \& Lissing, 2016; Pang \& Ruch, 2019a), schools/education (Lottman, Zawaly, \& Niemiec, 2016; Wingert et al., 2020), special populations (Sharp, Niemiec, \& Lawrence, 2016; Shogren et al., 2017), and personal development (Baer, 2015; Niemiec, 2012). The manualized and in-depth integration of mindfulness and character strengths is found in the evidence-based Mindfulness-Based Strengths Practice (MBSP) program by Niemiec (2014), based on the universal system of strengths referred to as the VIA Classification of character strengths (Peterson \& Seligman, 2004) and based on the latest research in the fields of mindfulness and character strengths individually. Two comparison studies showed MBSP is superior to the gold-

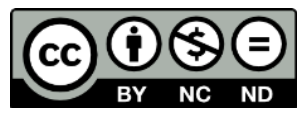

Copyright belongs to the author(s) www.internationaljournalofwellbeing.org 
standard mindfulness-based program, Mindfulness-Based Stress Reduction (MBSR), on the workplace outcome of employee performance using supervisory ratings (both fared equally to one another and superior to controls for well-being and stress) (Pang \& Ruch, 2019a) and in elevating certain character strengths such as humor (Hofmann et al., 2019). Other empirical studies found MBSP to be superior to controls in boosting flourishing, life satisfaction, engagement, and signature strengths use (Ivtzan, Niemiec, \& Briscoe, 2016), as well as showing significant improvements to engagement, health, well-being, and meaning, as well as increases in student retention at the collegiate level (Wingert et al., 2020).

Mindfulness-Based Strengths Practice (MBSP) is an 8-week program, with 2-hour sessions, delivered in weekly intervals, and with a 5-hour, experiential MBSP Retreat occurring a few days following Session 6. The most common delivery modalities of MBSP are groups in online or faceto-face settings, followed by use in individual counseling or coaching situations. The context for MBSP varies widely from the business setting, primary/secondary education setting, university setting, hospital/clinic setting, churches and spiritual centers, and community/civic environments. The first two sessions in the MBSP program are primers in mindfulness and character strengths, respectively, each introducing key concepts, rationale, unique and applicable research findings, and include experiential activities, meditations, and strengths discussions in small groups. Sessions 3 through 8 cover the integration of mindfulness and character strengths with the same range of teaching modalities. The foundational integration points involve the two main pathways for integration, described as "strong mindfulness" and "mindful strengths use" (Niemiec, 2014). Character strengths offer a unique opportunity to support or enhance mindfulness practices, meditation, and mindful living (i.e., strong mindfulness; Niemiec, 2012; Niemiec, Rashid, \& Spinella, 2012). For example, the use of perseverance or honesty can be used to stick with a sitting meditation practice, the use of gratitude or hope can reinvigorate a mindful walking practice, and bravery or judgment might help to overcome barriers and obstacles to mindfulness practices. In turn, the use of mindfulness is an important lens for becoming tuned in to one's best internal qualities (Bretherton \& Niemiec, 2020), overcoming blind spots to selfknowledge (Carlson, 2013), and pursuing balanced or optimal strengths use for the context (i.e., mindful strengths use). Said another way, mindful strengths use elicits the seeing and appreciating of one's own and others' character strengths, the recognition of strengths overuse and underuse, and supporting decisions on which strengths to use in particular situations/contexts.

Indeed, mindfulness and character strengths can have a powerful effect on one another (Duan \& Ho, 2017) and the integration model of the positive mutual effects has held up strongly in studies (Pang \& Ruch, 2019b). The integration of these constructs points participants in the direction of handling life obstacles and stressors, building strong and positive relationships, expressing oneself authentically, pursuing goodness, and living life with mindfulness and strength. Table 1 (below) offers the core topics/themes and short comments on each MBSP session. Included in this table is the MBSP retreat in which participants deepen their practices of mindful, strengths-based living, by bringing full and deep attention to listening, speaking, standing, walking, preparing food, eating, and character strengths use. 
Table 1. Core topic/theme areas of MBSP by session

\section{Session Core Topic/Theme Description}

\begin{tabular}{|c|c|c|}
\hline 1 & $\begin{array}{l}\text { Mindfulness and } \\
\text { Autopilot }\end{array}$ & $\begin{array}{l}\text { The autopilot mind is pervasive; insights and change } \\
\text { opportunities start with mindful attention. }\end{array}$ \\
\hline 2 & $\begin{array}{l}\text { Your Signature } \\
\text { Strengths }\end{array}$ & $\begin{array}{l}\text { Identify what is best in you; this can unlock potential to } \\
\text { engage more in work and relationships and reach higher } \\
\text { personal potential. }\end{array}$ \\
\hline 3 & $\begin{array}{l}\text { Obstacles are } \\
\text { Opportunities }\end{array}$ & $\begin{array}{l}\text { The practice of mindfulness and of strengths exploration } \\
\text { leads immediately to two things -obstacles/barriers to the } \\
\text { practice and a wider appreciation for the little things in life. }\end{array}$ \\
\hline 4 & $\begin{array}{l}\text { Strengthening } \\
\text { Mindfulness in } \\
\text { Everyday Life } \\
\text { (Strong } \\
\text { Mindfulness) }\end{array}$ & $\begin{array}{l}\text { Mindfulness helps us attend to and nourish the best, } \\
\text { innermost qualities in ourselves and others, while reducing } \\
\text { negative judgments of self and others; conscious use of } \\
\text { strengths can help us deepen and maintain a mindfulness } \\
\text { practice. }\end{array}$ \\
\hline 5 & $\begin{array}{l}\text { Valuing Your } \\
\text { Relationships }\end{array}$ & $\begin{array}{l}\text { Mindful attending can nourish two types of relationships: } \\
\text { relationships with others and our relationship with } \\
\text { ourselves. Our relationships with ourselves contributes to } \\
\text { self-growth and can have an immediate impact on our } \\
\text { connection with others. }\end{array}$ \\
\hline 6 & $\begin{array}{l}\text { Mindfulness of the } \\
\text { Golden Mean } \\
\text { (Mindful Strengths } \\
\text { Use) }\end{array}$ & $\begin{array}{l}\text { Mindfulness helps to focus on problems directly and } \\
\text { character strengths help to reframe and offer different } \\
\text { perspectives not immediately apparent. }\end{array}$ \\
\hline $\begin{array}{l}\text { Optional } \\
\text { Retreat }\end{array}$ & $\begin{array}{l}\text { MBSP 1/2-Day } \\
\text { Retreat }\end{array}$ & $\begin{array}{l}\text { Mindful living and character strengths apply not only to } \\
\text { good meditation practice but also to daily conversation, } \\
\text { eating, walking, sitting, reflecting, and the nuances therein } \\
\text { (e.g., opening the refrigerator door, turning a doorknob, } \\
\text { creating a smile). This day is therefore, a practice day. }\end{array}$ \\
\hline 7 & $\begin{array}{l}\text { Authenticity and } \\
\text { Goodness }\end{array}$ & $\begin{array}{l}\text { It takes character (e.g., courage) to be a more authentic } \\
\text { "you" and it takes character (e.g., hope) to create a strong } \\
\text { future that benefits both oneself and others. Set mindfulness } \\
\text { and character strengths goals with authenticity and } \\
\text { goodness in the forefront of the mind. }\end{array}$ \\
\hline 8 & $\begin{array}{l}\text { Your Engagement } \\
\text { with Life }\end{array}$ & $\begin{array}{l}\text { Stick with those practices that have been working well and } \\
\text { watch for the mind's tendency to revert back to automatic } \\
\text { habits that are deficit-based, unproductive, or that prioritize } \\
\text { what's wrong in you and others. Engage in an approach that } \\
\text { fosters awareness and celebration of what is strongest in you } \\
\text { and others. }\end{array}$ \\
\hline
\end{tabular}


There is an internal structure to each MBSP session (see Table 2). The sessions start with an opening meditation to bring their attention to the present moment. This is followed by small or large group discussion of "what went well" with the previous week's homework and practices; this often leads to what didn't go well and the management of obstacles and setbacks but without this starting point the negative from the week is likely to quickly overshadow the positive and good experiences (Baumeister et al., 2001; Rozin \& Royzman, 2001). This is followed by teaching input on the core theme (see Table 1) for the session and a related experiential activity, which is a central, embodied learning experience for the session. Next, participants engage in what's termed as the virtue circle (in some cultures, the practitioners use the term "strengths circle," "wisdom circle," or "appreciative circle") which is a structured experience of mindful speaking and listening and strengths-spotting while sharing insights from the session. The session concludes with a review of the suggested mindfulness and strengths homework activities, and a concluding meditation.

Table 2. Standard structure of MBSP sessions (Niemiec, 2014)

\begin{tabular}{|c|c|c|}
\hline Part & Focus Area & Description \\
\hline I & Opening meditation & $\begin{array}{l}\text { Start group with "practice," allows for letting } \\
\text { go of preceding tension and ushers in a } \\
\text { different focus. }\end{array}$ \\
\hline II & $\begin{array}{l}\text { Discussion: whole group or } \\
\text { multiple small groups }\end{array}$ & $\begin{array}{l}\text { Review participants' practice from last week } \\
\text { with the following catalyst: What went well? }\end{array}$ \\
\hline III & Lecture/input & $\begin{array}{l}\text { Offering new material aligned with core } \\
\text { themes. }\end{array}$ \\
\hline IV & Experiential & $\begin{array}{l}\text { Core practice with mindfulness and character } \\
\text { strengths is experienced. }\end{array}$ \\
\hline $\mathrm{V}$ & Virtue circle & $\begin{array}{l}\text { Structured, respectful approach for mindful } \\
\text { listening/speaking practice and strengths- } \\
\text { spotting/appreciating practice. }\end{array}$ \\
\hline VI & Suggested homework & Review of focus areas in between sessions. \\
\hline VII & Closing meditation & $\begin{array}{l}\text { Letting go of session to come fully into present } \\
\text { moment; mindful transitioning to the next part } \\
\text { of the day. }\end{array}$ \\
\hline
\end{tabular}

While there are a number of promising theoretical and empirical findings of MBSP, we are not aware of studies conducted with a primary focus at the qualitative level, which allows deeper understanding of the experiences of the participants during MBSP, what engages them in mindfulness and character strengths practices, what obstacles emerge in their practice, and their perceptions of the benefits that MBSP brings them. We aimed to explore the most common and impactful practices people engage in with mindfulness and character strengths, the most 
prevalent obstacles that serve as barriers to their daily practice, the relative importance of weekly attendance and homework, relevance of each of the areas of internal structure within an MBSP session, and perceived outcomes of MBSP (e.g., meaning, engagement, identity, relationships, stress management, problem management). Hence, qualitative and quantitative findings are shared.

\section{Method}

We describe and explore post program survey data $(\mathrm{N}=126)$ collected from adult participants who chose to participate in the 8-week MBSP program. Almost all participants paid for the program, and these programs span a six-year period, involving several countries, instructors, and groups. Some groups were conducted face-to-face in a given country while other groups were conducted entirely online with synchronous webinars and involved participants from up to 15 countries at a time, with all groups meeting weekly and coming together to learn the material. The majority were led by the second author in an online format from the United States, in addition data from other facilitators in the Netherlands and Australia are included here. The data was collected from a post-program form that includes some basic quantitative data, such as the effect of the program on overall well-being or management of stress (using a 7-point Likert scale with anchors of A Lot Higher/Better, No Change, and A Lot Worse/Lower), and several open ended questions, such as "Has this course had a positive effect on one of your relationships? If so, please explain.", or "What has struck you most about the course?". A standard part of the MBSP program is to complete the post-program form, which does not include demographic or identifying information. It is also standard MBSP practice to inform the participants that the form is voluntary, confidential, and is used for MBSP research. The VIA Institute on Character, which collected the MBSP data in this paper, is an independent, non-university, non-profit organization, and did not pursue IRB approval for the MBSP post-program form (see Appendix A).

The first author who did not teach or participate in any of the MBSP groups analyzed both the quantitative and qualitative data to ensure objectivity. Three open-ended, no-word-limit, text-only questions were used for qualitative analysis: 1) "Has this course had a positive effect on one of your relationships? If so, please share:" and 2) "What has struck you most about this course? Please share below:", and 3) "As you think about the "virtue circle" (in which participants share their learning, insights, and or questions) were there any benefits of this experience? Please explain." In manually analyzing the qualitative data (Huberman, Miles, \& Saldana, 2019), all responses were read and descriptively coded to create summary labels for data, such as participants description of being self-compassionate. Then iterative readings of the data and analysis of the codes were used to ensure consistent coding and to identify and count the most common codes or themes.

As previously stated, our focus in this manuscript is the outcomes and experiences of the participants in order to increase the understanding of integrating mindfulness and character strengths practices. Additional information on the MBSP design and participant experience is available from the authors.

\section{Results}

We summarize the results in six categories: practices created, meditation obstacles, outcomes, positive relationships, inward- and outward-oriented practices, and cognizance of the integration of mindfulness and character strengths. The results on the qualitative and quantitative items were as follows: 


\subsection{Practices created}

One of the best ways to improve mindfulness is to engage in a regular meditation practice; this approach has been championed by the leading mindfulness-based programs (Kabat-Zinn, 1990; Niemiec, 2014; Segal, Williams, and Teasdale, 2013) and is central to character strengths intervention approaches as well (Niemiec, 2018). In other words, make mindfulness part of one's mindset and routine of daily life. The approach to working with character strengths offers a similar emphasis on practice and integrating that practice into one's life (Niemiec, 2018). Of a myriad of potential ways to engage in mindfulness and strengths practices, 10 general approaches were selected and offered to participants to check what they did on a regular basis. Table 3 shows these results. The top regular practices were the assigned mindfulness meditation each week (84\%), observing their own and others' strengths (79\%), appreciating others' strengths $(71 \%)$, working on one's own strengths $(70 \%)$, and reflecting on past experiences with strengths $(56 \%)$. An additional finding was that $100 \%$ of people engaged in at least one regular practice.

Table 3. Mindfulness and character strengths practices practiced regularly during the MBSP program as rated on "Check all that apply" question ( $\mathrm{N}=118$ as one MBSP program did not include this specific question.)

\begin{tabular}{lll}
\hline Practice & Count & Percentage \\
\hline Mindfulness Meditation & 106 & $84 \%$ \\
\hline Observing Your and Others' Strengths & 100 & $79 \%$ \\
\hline Appreciating Other Strengths & 89 & $71 \%$ \\
\hline Working with Strengths & 88 & $70 \%$ \\
\hline Reflecting on Past Experiences with Strengths & 70 & $56 \%$ \\
\hline Discussing Strengths with Others & 58 & $46 \%$ \\
\hline Asking Others for Feedback & 43 & $34 \%$ \\
\hline Tracking/Monitoring Your Behaviors/Practices & 44 & $35 \%$ \\
\hline Planning Out Your Practices & 33 & $26 \%$ \\
\hline Journaling & 28 & $22 \%$ \\
\hline
\end{tabular}

When asked in an open-ended question about their favorite strengths practice, 37 (29\%) wrote in the character strengths 360 experience, which is a systematic approach in which the individual gathers feedback on others' perceptions and stories of their top strengths and then integrates that feedback in a meaningful way. This was followed by 27 (21\%) indicating strengths-spotting as a favorite practice, which involves the specific identification of strengths in others. For the openended question about favorite mindfulness experience, 28 (22\%) indicated the loving-kindness meditation, which involves the cultivation of strengths such as love and gratitude within oneself. The character strengths breathing space was next with 22 (17\%); this short meditation involves the targeting of 3 character strengths at the core of most meditations - curiosity, self-regulation, and perspective.

\subsection{Meditation obstacles}

One of the most challenging elements of mindfulness practice is keeping it up. There are numerous obstacles of the body (e.g., painful sensations), mind (e.g., mind wandering), environment (e.g., too many noises), and logistics (e.g., not enough time). Ten of the most common obstacles (Allen et al., 2009; Birtwell et al. 2019) were offered for participants to consider 
(along with a write-in option), and to check all that apply. The most common obstacles to meditation practice were not enough time/too busy to practice (52\% of participants), forgetting to practice (47\% of participants), and mind wandering (33\% of participants). Table 4 provides the percentage for each obstacle queried. These obstacles are not dissimilar to other mindfulness studies on meditation difficulties or challenges (Allen et al., 2009; Birtwell et al. 2019).

Table 4. Obstacles to mindfulness practice as rated on "Check all that apply" question

\begin{tabular}{lll}
\hline Mindfulness Obstacle & Count & Percentage \\
\hline Not enough time/too busy & 66 & $52 \%$ \\
\hline Often forgot to practice/schedule & 59 & $47 \%$ \\
\hline Mind wandered too much & 41 & $33 \%$ \\
\hline Kept falling asleep & 12 & $10 \%$ \\
\hline Wanted to avoid troubling thoughts/memories & 10 & $8 \%$ \\
\hline Too bothered by the external (e.g., noises) & 10 & $8 \%$ \\
\hline Wanted to avoid difficult emotions & 7 & $6 \%$ \\
\hline Did not see the purpose in practicing & 5 & $4 \%$ \\
\hline Wanted to avoid painful sensations & 4 & $3 \%$ \\
\hline It was not very helpful/beneficial & 3 & $2 \%$ \\
\hline Other & 1 & $<1 \%$ \\
\hline
\end{tabular}

\subsection{Outcomes}

There are a number of positive outcomes associated with mindfulness practice alone (Sedlmeier et al., 2012), character strengths practice alone (Schutte \& Malouff, 2019), and mindfulness and character strengths (MBSP) together (Pang \& Ruch, 2019a). MBSP participants were asked whether they perceived a direct effect of MBSP in their life across a number of valued outcomes that reflect areas of well-being and adversity. These included overall well-being, sense of who you are, engagement with life tasks, sense of accomplishment, meaning in life, sense of purpose, quality of relationships, management of stress, and management problems. All but one participant (99\%) reported at least one positive impact of MBSP on their life.

More specifically, using a Likert scale from 1 to 7 where 7 means "A lot higher/better" and 1 means "A lot worse/lower" and 4 means "No change," 91\% of participants reported a positive change of well-being (see Table 5 below). In addition, the following percentages of positive change were reported: sense of who you are (90\%), engagement with life tasks (84\%), accomplishment $(74 \%)$, meaning in life $(81 \%)$, sense of purpose $(84 \%)$, relationship quality $(86 \%)$, stress management $(84 \%)$, and problem management $(87 \%)$. The percentage of participant responses that indicated a negative change (a score of 3, 2, or 1 on a 7-point Likert scale) to any of the 9 outcomes was less than $1 \%(.003 \%)$. The latter is an important percentage to note as programs, even mindfulness and strengths ones, should always assess for negative effects, or side effects of the program. 
Table 5. Positive outcomes attributed to MBSP, as rated on a likert scale of 1-7, by Participants ( $N=118$ as one MBSP program did not include this specific question.)

\begin{tabular}{|c|c|c|c|c|c|c|c|c|c|}
\hline & $\begin{array}{c}\text { Overall } \\
\text { Well- } \\
\text { being }\end{array}$ & $\begin{array}{c}\text { Sense } \\
\text { of } \\
\text { Who } \\
\text { You } \\
\text { Are }\end{array}$ & $\begin{array}{c}\text { Engage- } \\
\text { ment } \\
\text { with } \\
\text { Life } \\
\text { Tasks }\end{array}$ & $\begin{array}{l}\text { Sense } \\
\text { of } \\
\text { Accom- } \\
\text { plish- } \\
\text { ment }\end{array}$ & $\begin{array}{c}\text { Meaning } \\
\text { in Life }\end{array}$ & $\begin{array}{c}\text { Sense } \\
\text { of } \\
\text { Pur- } \\
\text { pose }\end{array}$ & $\begin{array}{l}\text { Quality } \\
\text { of Your } \\
\text { Relat- } \\
\text { ionships }\end{array}$ & $\begin{array}{c}\text { Manage- } \\
\text { ment } \\
\text { of } \\
\text { Stress }\end{array}$ & $\begin{array}{c}\text { Manage- } \\
\text { ment } \\
\text { of } \\
\text { Problems }\end{array}$ \\
\hline $\begin{array}{l}\text { Percentage } \\
\text { Responding }\end{array}$ & & & & & & & & & \\
\hline $5-7$ & $91 \%$ & $90 \%$ & $84 \%$ & $74 \%$ & $81 \%$ & $84 \%$ & $86 \%$ & $84 \%$ & $87 \%$ \\
\hline $\begin{array}{l}1 \text { A Lot } \\
\text { Worse/Lower }\end{array}$ & 0 & 0 & 0 & 0 & 0 & 0 & 0 & 0 & 0 \\
\hline 2 & 0 & 0 & 1 & 0 & 0 & 0 & 0 & 0 & 0 \\
\hline 3 & 0 & 0 & 1 & 1 & 0 & 0 & 0 & 0 & 0 \\
\hline 4 No Change & 5 & 9 & 15 & 28 & 19 & 16 & 13 & 18 & 12 \\
\hline 5 & 41 & 34 & 36 & 33 & 39 & 35 & 38 & 38 & 41 \\
\hline 6 & 53 & 49 & 45 & 42 & 42 & 47 & 53 & 49 & 49 \\
\hline $\begin{array}{l}7 \text { A Lot } \\
\text { Higher/Better }\end{array}$ & 13 & 23 & 18 & 12 & 15 & 17 & 10 & 12 & 13 \\
\hline
\end{tabular}

\subsection{Positive relationships}

Both the quantitative and qualitative data indicated a strong impact on positive relationships. First, $86 \%$ of participants rated an improvement in the quality of their relationships. Next, when asked about the impact of the program on one of their specific relationships, the participants were required to write in their response. For this item, $67 \%$ of participants wrote in an affirmative response specifying one of their relationships that substantially improved or made general comments about improvement overall in their relationships. This means that $33 \%$ of participants left this question blank so we do not know whether or how MBSP affected their relationships. A few examples are offered.

"I feel I am much more present with my family. Helped me to appreciate my 'whole self'."

"It has helped me be more mindful of and appreciative of the full scope of character strengths in others and myself."

"It has - with clients, friends, family, and spouse. I understand and appreciate others more; I feel hopeful."

Participants also described their strengths and mindfulness practices positively impacting their ability to process and or resolve conflict in relationships.

"Yes, I am more able to talk about struggles with my family and loved ones."

"MBSP allowed me to step back and adopt a curious attitude about a person who has been pushing my buttons lately. I go to the breath a few times, then ask myself about the person's strengths. The result is I can see the person coming from a place of love, rather than a place of greed."

"MBSP has helped me be more mindful about choice over reaction."

In addition to positive relationships with others, participants also described being more selfcompassionate and appreciating their own strengths.

"The most positive effect has been on the relationship with myself."

"Yes, with myself first and then my appreciation of others." 
"My relationship with myself - and seeing some strengths in me that old family relationships had denied - was uplifting."

"My relationship with myself under stress. I'm more mindful of stress responses and view myself with more kindness."

Diener and Seligman (2004) note the crucial role of relationships to well-being and this is a central pathway in flourishing theories and studies (Wagner et al., 2019). Our data show a substantial improvement in relationships with others across participant self-ratings (quantitative) and their descriptions of how they improved their relationships (qualitative). This appears to be a novel and important result in the MBSP experience, and more widely, for the mindfulness literature where the variable of positive relationships is not one of the common areas explored.

\subsection{Inward- and outward-oriented practices}

In an examination of different ways of practicing with mindfulness and character strengths, both inward and outward expressions emerged. Based on both quantitative and qualitative data, participants appeared to develop both an expression of character strengths inward toward themselves as well as an expression of character strengths outward toward others. In regard to an inward focus, $69 \%$ of participants became more aware of their signature strengths, $67 \%$ used their character strengths more often, and $67 \%$ deepened their mindfulness practice (see Table 6 below for additional changes made by participants and attributed to MBSP). For example, these are reflected in participants observations about inward work relating to authenticity and their true self.

Welcoming back my true self. Realising that I was running away from my core strengths and now using them wisely. It was a total turn around.

Importance of all the strengths and how understanding them all gives me more tools to work with.

These inward-focused experiences are also seen in participants describing an increased sense of purpose (84\%) and understanding of "who you are" (90\%).

The tangible improvement in well-being and the sense [of] self-agency I have in meaningful application of my strengths.

More reminding myself of walking in authenticity. I aspire to be mindfully authentic, shifting from "doing" the work to becoming the work, expressing virtues in authenticity in daily action.

Through MBSP, I've really amped up my mindfulness practice. In combination with character strengths, this helps me become a better person, live a better life, and create a ripple effect to others.

It has opened up my mind to a whole new level of creativity and purpose.

Engaging in practices between sessions (i.e., homework exercises) is an important part of the inner journey of MBSP. Indeed, home practice has been shown in mindfulness studies to predict positive outcomes (Lloyd et al., 2018; Vettese et al., 2009). When asked about the percentage of homework the participants completed each week on average, the modal response was $75 \%$ and the percentage of participants who completed between $50-90 \%$ of the activities was $73 \%$ of participants. In reflecting on their experiences during the program, homework activities that explicitly involved interacting with other people mindfully, such as the strengths interview (in which participants choose one person to interview about their strengths), strengths-spotting, and 
the character strengths 360 were the three favorite strengths practices freely noted by participants (not prompted). In an open-ended question, 29\% of participants identified the Character Strengths 360 as their favorite activity, in one case describing it as "transformational." Receiving feedback from others on our strengths lets us understand our strengths and use of them in ways that individual reflection typically does not provide, and it offers a means to deepen strengths practice overall and in specific contexts, e.g., in the workplace or family.

Table 6. Personal changes in mindfulness and character strengths attributed to MBSP by participants as rated on "Check all that apply" question

\begin{tabular}{|c|c|c|}
\hline Practice/Activity & Count & Percentage \\
\hline Spot strengths in others frequently & 99 & $79 \%$ \\
\hline $\begin{array}{l}\text { Use my strengths to deal with my problems/ } \\
\text { difficulties }\end{array}$ & 91 & $72 \%$ \\
\hline Am aware of my signature strengths & 87 & $69 \%$ \\
\hline Have deepened my mindfulness practice & 84 & $67 \%$ \\
\hline Use my strengths more often & 85 & $67 \%$ \\
\hline Verbally appreciate strengths more in others & 73 & $58 \%$ \\
\hline $\begin{array}{l}\text { Use mindfulness to face my problems/ } \\
\text { difficulties }\end{array}$ & 72 & $57 \%$ \\
\hline Started a new mindfulness practice & 56 & $44 \%$ \\
\hline $\begin{array}{l}\text { Overcome more obstacles in my mindfulness } \\
\text { practice }\end{array}$ & 55 & $44 \%$ \\
\hline I made no changes because of this group & 0 & $0 \%$ \\
\hline
\end{tabular}

In terms of outward-focused activities, $79 \%$ of participants regularly practiced strengths-spotting in others, while $72 \%$ used strengths to deal with problems/difficulties. Participants explained:

"I appreciate other people's strengths more and tell them."

"At work - seeing strengths instead of differences."

"How people shine when you strength spot them."

In using strengths to deal with difficulties, participants observed:

"I don't seem to take things so personally anymore, if that makes sense? This goes for work, too, I speak my mind more, and am perhaps less of a pushover."

"Yes, I have been treating my mother more kindly rather than out of frustration for her inabilities and high expression of anxiety."

\subsection{Cognizance of the integration of mindfulness and character strengths}

When participants were asked whether they cared most about learning about mindfulness, about character strengths, or about the integration of these areas, $71 \%$ reported they were most interested in the integration of mindfulness and character strengths. In addition, when asked in a separate question what they believe is true for them, the majority of participants, $77 \%$, indicated they believed that mindfulness will help their character strengths use and expression, while $69 \%$ believed character strengths will help their mindfulness practice, and $62 \%$ believed integration was essential for practicing either. Meanwhile, only $1.6 \%$ of participants did not align with any of these three statements, indicating an overwhelming majority understood the integration and could see the impact therein. 
We did not ask a specific question about the development of the integration areas of mindful strengths use or strong mindfulness, however, several participants directly spoke to these terms. For example, in the open-ended question asking, "What has struck you most about this course?" eight participants explicitly described mindful strengths use while three explicitly described strong mindfulness. For mindful strengths use, participants noted:

"I appreciate the most how mindfulness can boost the character strengths..."

"Now that I've experienced mindful strengths use in practice, I can truly see the amazing benefit of integration of the two concepts."

"I love to be mindful of strengths when facing a challenge."

An example of strong mindfulness included:

"I was struck by how to use character strengths during mindfulness practices. Helps me to do it [mindfulness] more consciously."

\section{Discussion and future directions}

There are a number of interesting findings in these results. We discuss the results from the previous section alongside directions for future research. Participants developed a range of practices in mindfulness and character strengths. Engaging in a regular practice is central to all mindfulness-based programs (Kabat-Zinn, 1990, Niemiec, 2014; Segal, Williams, \& Teasdale, 2013). Large percentages of participants reported engaging in regular mindfulness practices $(84 \%)$ and character strengths practices such as observing their own and others' strengths (79\%), appreciating others' strengths (71\%), and working on one's own strengths (70\%). Future research might deploy dismantling procedures to examine the most active ingredients of MBSP, as MBSP includes a variety of mindfulness and strengths-based activities, meditations, and discussions. A recent study took a dismantling approach to examine two mindfulness-based programs, MBSR and MBCT (mindfulness-based cognitive therapy) (Stein \& Witkiewitz, 2020).

The most common obstacles to mindfulness practice, by far, were participants not having enough time/too busy, forgetting to practice, and mind wandering. The other obstacles, such as falling asleep, being bothered by noises, or having troublesome thoughts/memories were reported but these and other obstacles remained at $10 \%$ or less of participants. This tells us that mindfulness teachers and students might directly target these three common obstacles in order to support the largest number of people in mindfulness-based programs. The MBSP program addresses this with the integration area, strong mindfulness, in which participants practice using their character strengths to confront and overcome their personal meditation obstacles. For example, a person might use curiosity to explore their mind wandering, prudence and selfregulation in the disciplining to schedule their practice, and perspective to overcome a sense of not enough time, or add gratitude and hope to their practice in order to feel more motivated to practice amidst their busy day. Indeed, $44 \%$ of participants reported overcoming more obstacles in their mindfulness practice during the program. Future research might target one specific obstacle and analyze the most optimal character strengths of the 24 to help overcome or manage it.

There were a number of positive outcomes revealed by the data. In addition to over $99 \%$ of participants reporting some substantial positive outcome, high percentages were found for each specific area assessed. The five well-being pathways of a leading well-being theory, PERMA (Seligman, 2011) can be seen as reflected in the MBSP outcomes, particularly the areas of engagement, relationships, meaning, and achievement (the area of positive emotions was not measured). In addition, a leading theory of character strengths explains the major functions of 
character strengths as being linked with two overarching areas: opportunity (e.g., creating wellbeing) and adversity (Niemiec, 2019). As the former area was just discussed, the latter area, adversity, was also assessed by asking participants about the perceived impact of MBSP on their stress management and their problem management. Large percentages of respondents expressed a positive impact on their stress management (84\%) and their management of problems (87\%). This is similar to the positive impact of MBSP on different forms of adversity in controlled studies, such as stress (e.g., Pang \& Ruch, 2019a) and loneliness (e.g., Wingert et al. 2020). The inward-oriented and outward-oriented approach was another positive outcome, as our data show that participants found a balance in establishing practices to benefit themselves (i.e., inward) and to benefit others (i.e., outward).

Another positive outcome was the impact of MBSP on positive relationships. This was a substantial finding on both quantitative and qualitative levels. In addition to high self-ratings $(86 \%)$ of participants reporting MBSP positively impacted one of their relationships, a majority of participants $(67 \%)$ who were willing to write in a response of a specific positive impact, such as individual relationships (e.g., parent, child, or colleague) or a general group (e.g., family) that was positively impacted and with a specific change (e.g., able to be more patient or able to better understand another person). Other findings dovetail with this positive relationships outcome. For example, the high frequency of participants engaging in strengths-spotting and strengthsappreciation lends itself to the building of positive relationships. With the emphasis of mindfulness studies veering toward targeting stress and well-being, we find this positive and substantial impact on relationships to be a novel and important finding.

Future research might explore the specifics of how and why the relationships are more positive. In MBSP multiple variables are involved such as meditation practice, mindful living practice, character strengths awareness and use, and multiple in-course and home-practice activities on the integration of these areas. Given that positive relationships and meaning/purpose are two of the strongest predictors of overall well-being (e.g., Diener \& Seligman, 2004; Wagner et al., 2019), it is not surprising that participants reported better overall well-being. It would be interesting to investigate the mechanisms by which the integration of mindfulness and character strengths impact meaning in life, purpose, achievement, and other variables that participants reported elevating at the end of the program.

An important contribution of the MBSP program is the novel integration of mindfulness and character strengths, discussed throughout as strong mindfulness and mindful strengths use. Theoretically, these areas of integration have good emerging evidence (e.g., Duan \& Ho, 2017; Pang \& Ruch, 2019b). Mindfulness has been discussed as an important pathway in helping people understand their self-knowledge - who they are, in that it can help people overcome the barriers in how they view themselves and process information about themselves (Carlson, 2013). Participants resonated with the integration and readily engaged in practices relating to both strong mindfulness and mindful strengths use. Future research might develop an assessment tool for measuring these two integration pathways. This would open up additional research examining the impact of MBSP (or other mindfulness-based programs) on these dynamics as well as exploring the ease by which the pathways develop, differential outcomes, and capacity for sustaining each area of integration.

\section{Acknowledgements}

The authors wish to thank the MBSP leaders from various countries who contributed to these data and all the other MBSP leaders who continue to inspire us. We also wish to thank Palmer Berry for her data entry work. 


\section{Authors}

Karen Whelan-Berry

University of Massachusetts Amherst

karenswb@gmail.com

Ryan Niemiec

VIA Institute on Character

\section{Publishing Timeline}

Received 11 January 2021

Revised version received 13 April 2021

Accepted 19 April 2021

Published 31 May 2021

\section{References}

Allen, M., Bromley, A., Kuyken, W., \& Sonnenberg, S. J. (2009). Participants' experiences of mindfulnessbased cognitive therapy: "It changed me in just about every way possible." Behavioural and Cognitive Psychotherapy, 37, 413-430. https://doi.org/10.1017/S135246580999004X

Baer, R. (2015). Ethics, values, virtues, and character strengths in mindfulness-based interventions: A psychological science perspective. Mindfulness, 6, 956-969. https://doi.org/10.1007/s12671-015-0419-2

Baumeister, R. F., Bratslavsky, E., Finkenaeuer, C., \& Vohs, K. D. (2001). Bad is stronger than good. Review of General Psychology, 5(4), 323-370. https://doi.org/10.1037/1089-2680.5.4.323

Birtwell, K., Williams, K., van Marwijk, H., Armitage, C. J., \& Sheffield, D. (2019). An exploration of formal and informal mindfulness practice and associations with wellbeing. Mindfulness, 10, 89-99. https://doi.org/10.1007/s12671-018-0951-y

Bretherton, R., \& Niemiec, R. M. (2020). Mindfulness-based strengths practice. In I. Ivtzan (Ed.), Mindfulness-based programmes (pp. 385-402). New York: Routledge. https://doi.org/10.4324/9781315265438-30

Carlson, E. N. (2013). Overcoming the barriers to self-knowledge: Mindfulness as a path to seeing yourself as you really are. Perspectives on Psychological Science, 8(2), 173-186. https://doi.org/10.1177/1745691612462584

Diener, E., \& Seligman, M. E. P. (2004). Beyond money: Toward an economy of well-being. Psychological Science in the Public Interest, 5(1), 1-31. https://doi.org/10.1111/j.0963-7214.2004.00501001.x

Duan, W., \& Ho, S. M. Y. (2017). Does being mindful of your character strengths enhance psychological wellbeing? A longitudinal mediation analysis. Journal of Happiness Studies. https://doi.org/10.1007/s10902-017-9864-z

Hofmann, J., Heintz, S., Pang, D., \& Ruch, W. (2019). Differential relationships of light and darker forms of humor with mindfulness. Applied Research in Quality of Life, 15, 369-393. https://doi.org/10.1007/s11482-018-9698-9

Ivtzan, I., Niemiec, R. M., \& Briscoe, C. (2016). A study investigating the effects of Mindfulness-Based Strengths Practice (MBSP) on wellbeing. International Journal of Wellbeing, 6(2), 1-13. https://doi.org/10.5502/ijw.v6i2.1

Kabat-Zinn, J. (1990). Full catastrophe living. New York, NY: Dell.

Lottman, T., Zawaly, S., \& Niemiec, R. M. (2017). Well-being and well-doing: Bringing mindfulness and character strengths to the early childhood classroom and home. In C. Proctor (Ed.), Positive psychology interventions in practice (pp. 83-105). Cham, Switzerland: Springer. https://doi.org/10.1007/978-3-319-51787-2_6

Miles, M.B., Huberman, A. M., \& Saldana, J. (2019). Qualitative data analysis: A methods sourcebook, 2 nd edition. Thousand Oaks CA: Sage Publications.

Niemiec, R. M. (2012). Mindful living: Character strengths interventions as pathways for the five mindfulness trainings. International Journal of Wellbeing, 2(1), 22-33. https://doi.org/10.5502/ijw.v2i1.2 
Niemiec, R. M. (2014). Mindfulness and character strengths: A practical guide to flourishing. Boston, MA: Hogrefe.

Niemiec, R. M. (2018). Character strengths interventions: A field-guide for practitioners. Boston: Hogrefe. https://doi.org/10.1027/00492-000

Niemiec, R. (2019). Six functions of character strengths for thriving at times of adversity and opportunity: A theoretical perspective. Applied Research in Quality of Life, 15, 551-572 https://doi.org/10.1007/s11482-018-9692-2

Niemiec, R. M., \& Lissing, J. (2016). Mindfulness-based strengths practice (MBSP) for enhancing wellbeing, life purpose, and positive relationships. In I. Ivtzan \& T. Lomas (Eds.), Mindfulness in positive psychology: The science of meditation and wellbeing (pp. 15-36). New York: Routledge.

Niemiec, R. M., Rashid, T., \& Spinella, M. (2012). Strong mindfulness: Integrating mindfulness and character strengths. Journal of Mental Health Counseling, 34(3), 240-253. https://doi.org/10.17744/mehc.34.3.34p6328x2v204v21

Pang, D., \& Ruch, W. (2019a). Fusing character strengths and mindfulness interventions: Benefits for job satisfaction and performance. Journal of Occupational Health Psychology, 24(1), 150-162. https://doi.org/10.1037/ocp0000144

Pang, D., \& Ruch, W. (2019b). The mutual support model of mindfulness and character strengths. Mindfulness. DOI: https://doi.org/10.1007/s12671-019-01103-z

Peterson, C., \& Seligman, M. E. P. (2004). Character strengths and virtues: A handbook and classification. New York: Oxford University Press, and Washington, DC: American Psychological Association.

Rozin, P., \& Royzman E. B. (2001). Negativity bias, negativity dominance, and contagion. Personality and Social Psychology Review, 5(4), 296-320. https://doi.org/10.1207/S15327957PSPR0504_2

Schutte, N. S., \& Malouff, J. M. (2019). The impact of signature character strengths interventions: A metaanalysis. Journal of Happiness Studies, 20(4), 1179-1196. https://doi.org/10.1007/s10902-018-9990-2

Sedlmeier, P., Eberth, J., Schwarz, M., Zimmermann, D., Haarig, F., Jaeger, S., \& Kunze, S. (2012). The psychological effects of meditation: A meta-analysis. Psychological Bulletin, 138 (6),1139-1171.

Segal, Z. V., Williams, J. M. G., \& Teasdale, J. D. (2013). Mindfulness-based cognitive therapy for depression: A new approach to preventing relapse ( $2^{\text {nd }}$ ed.). New York, NY: Guilford.

Seligman, M. E. P. (2011). Flourish. New York, NY: Free Press.

Sharp, J. E., Niemiec, R. M., \& Lawrence, C. (2016). Using mindfulness-based strengths practices with gifted populations. Gifted Education International. http://doi.org/10.1177/0261429416641009

Shogren, K. A., Singh, N., Niemiec, R. M., \& Wehmeyer, M. (2017). Character strengths and mindfulness. In M. Wehmeyer (Ed.), Oxford handbooks online. https://doi.org/10.1093/oxfordhb/9780199935291.013.77

Stein, E., \& Witkiewitz, K. (2020). Dismantling mindfulness-based programs: A systematic review to identify active components of treatment. Mindfulness https://doi.org/10.1007/s12671-020-01444-0

Vettese, L. C., Toneatto, T., Stea, J. N., Nguyen, L., \& Wang, J. J. (2009). Do mindfulness meditation participants do their homework? And does it make a difference? A review of the empirical evidence. Journal of Cognitive Psychotherapy, 23(3), 198-225. https://doi.org/10.1891/0889-8391.23.3.198

Wagner, L., Gander, F., Proyer, R. T., \& Ruch, W. (2019). Character strengths and PERMA: Investigating the relationships of character strengths with a multidimensional framework of well-being. Applied Research in Quality of Life. https://doi.org/10.1007/s11482-018-9695-z

Wingert, J. R., Jones, J. C., Swoap, R. A., \& Wingert, H. M. (2020). Mindfulness-based strengths practice improves well-being and retention in undergraduates: A preliminary randomized controlled trial. Journal of American College Health. Advance online publication.

https://doi.org/10.1080/07448481.2020.1764005 


\section{Appendix A. MBSP post-program form}

As previously noted, the VIA Institute on Character, which collected the MBSP data in this paper, is an independent, non-university, non-profit organization, and did not pursue IRB approval for the MBSP post-program form. When asking the participants to complete the post-program form during the final session, the instructor verbally notes that post-program form is confidential, voluntary, and will be used to support strengthening the MBSP program and advancing the science, research, and practice of MBSP. All MBSP participants are eighteen year of age or older, and the form does not include any demographic or identifying information. The form only includes questions about participants' experience in the program; mindfulness, strengths, and integrated practices that were developed or strengthened; obstacles to mindfulness encountered; and participants' perception of the impact the program had, for example, on their wellbeing and or relationships. 